\title{
COVID-19 Related Central Nervous System Vasculopathy: Beyond Vasculitis
}

I read with great interest the article by Hanafi et $\mathrm{al}^{1}$ reporting the case of a patient with coronavirus disease 2019 (COVID-19) who developed multiple focal supra- and infratentorial ischemic lesions involving the periventricular white matter, basal ganglia, cerebellar peduncles, and the corpus callosum. The authors considered hypoxic-ischemic injury as an unlikely mechanism, given the temporal mismatch between hypoxemia and neurologic deterioration, as well as imaging studies excluding involvement of the striatum and brain cortex. They also excluded a prothrombotic state because coagulation panel findings were normal. Because there was an association between ischemic and hemorrhagic lesions with patchy enhancement after intravenous contrast administration, the possibility of injury to small intracranial vasculature in the distribution of distal perforating arteries in a pattern suggestive of vasculitis was suggested.

I would like to share some comments on this case, in the hope of adding some more useful insights.

In Severe Acute Respiratory Syndrome coronavirus 2 (SARS$\mathrm{CoV}-2$ ) infection, vascular injury can occur through 2 potentially complementary mechanisms: direct, resulting from the virus affinity to angiotensin-converting enzyme-2 expressed by endothelial cells; ${ }^{2}$ and indirect, due to a misdirected host immune response inducing coagulopathy and vasoconstriction. ${ }^{3}$ Despite having a negative coagulation panel, the patient had elevated C-reactive protein $(60 \mathrm{mg} / \mathrm{L})$ and, very likely, a cytokine storm, as severely ill patients with COVID-19 typically present with it; ${ }^{4}$ these are known inflammatory markers that potentially induce hypercoagulability ${ }^{4}$ and endothelial cell injury per se. Moreover, Hanafi et al $^{1}$ could have stated which specific coagulation/inflammatory parameters were determined, as there are many described in the literature as

- Indicates open access to non-subscribers at www.ajnr.org

http://dx.doi.org/10.3174/ajnr.A6913 being abnormally high in patients with COVID-19, such as ferritin, D-dimer, or lactate dehydrogenase levels.

Simultaneously, to assertively diagnose vasculitis, one should document vessel lumen irregularities and, most important, vessel wall inflammation. Given the apparent small-vessel involvement, due to the topographic distribution of the aforementioned ischemic lesions, digital subtraction angiography could have been performed to characterize potential distal vessel irregularities (in this context, a more sensitive technique than 3D time-of-flight MRA); moreover, despite less sensitivity for small-vessel involvement, vessel wall MR imaging should ideally have been performed to search for concentric vessel wall enhancement, a known direct sign of regional mural inflammation. Therefore, in this case, the association of ischemic/ hemorrhagic lesions and the patchy enhancement pattern is, in my opinion, insufficient to establish the diagnosis of vasculitis.

Therefore, I believe one should be cautious and more conservative and describe this condition as a COVID-19 related vasculopathy, potentially induced by a misdirected host immune response in a probable setting of a cytokine storm.

\section{REFERENCES}

1. Hanafi R, Roger PA, Perin B, et al. COVID-19 neurologic complication with CNS vasculitis-like pattern. AJNR Am J Neuroradiol 2020;41:138487 CrossRef Medline

2. Varga Z, Flammer AJ, Steiger P, et al. Endothelial cell infection and endotheliitis in COVID-19. Lancet 2020;395:1417-18 CrossRef Medline

3. Zhou F, Yu T, Du R, et al. Clinical course of risk factors for mortality of adult inpatients with COVID-19 in Wuhan, China: a retrospective cohort study. Lancet 2020;395:1054-62 CrossRef Medline

4. Zubair AS, McAlpine LS, Gardin T, et al. Neuropathogenesis and neurologic manifestations of the coronaviruses in the age of coronavirus disease 2019: a review. JAMA Neurol 2020;77:1018-27 CrossRef Medline

(1) M. Quintas-Neves Neuroradiology Department Hospital de Braga Braga, Portugalv 